\title{
Evaluation at the Level of Health Facilities, of the Protective Efficacy of LLINs in Children under 5 Years Old from Localities of Low and High Resistance of Vectors to Pyrethroid Insecticides in Benin in West Africa
}

\author{
Tokponnon Tatchémè Filémon",2,3,4, Ossè Razaki1,5, Arthur Sovi1, Wakpo Abel6, \\ Hounto Ogouyémi Aurore ${ }^{6,7}$, Sissinto Yolande6, Adechoubou Alioun7, Houansou Télesphore \\ Oke Mariam², Kinde-Gazard Dorothée6, Massougbodji Achille6, Akogbeto Martin²
}

${ }^{1}$ Centre de Recherche Entomologique de Cotonou (CREC), Cotonou, Benin

${ }^{2}$ Ministry of Health, Cotonou, Benin

${ }^{3}$ Centre Béninois de le Recherche Scientifique et de l'Innovation, Cotonou, Benin

${ }^{4}$ Ecole Polytechnique d'Abomey-Calavi, Université d'Abomey-Calavi, Abomey-Calavi, Bénin

${ }^{5}$ Ecole de Gestion et d'exploitation des systèmes d'élevage, Université Nationale d'Agriculture, Kétou, Benin

${ }^{6}$ Faculté des Sciences de la Santé de l'Université d'Abomey Calavi, Cotonou, Benin

${ }^{7}$ National Malaria Control Programme, Cotonou, Benin

${ }^{8}$ World Health Organization, Cotonou, Benin

Email: filemont@yahoo.fr

How to cite this paper: Filémon, T.T., Razaki, O., Sovi, A., Abel, W., Aurore, H.O., Yolande, S., Alioun, A., Télesphore, H., Mariam, O., Dorothée, K.-G., Achille, M. and Martin, A. (2022) Evaluation at the Level of Health Facilities, of the Protective Efficacy of LLINs in Children under 5 Years Old from Localities of Low and High Resistance of Vectors to Pyrethroid Insecticides in Benin in West Africa. Advances in Infectious Diseases, 12, 57-73.

https://doi.org/10.4236/aid.2022.121005

Received: December 27, 2021

Accepted: February 27, 2022

Published: March 2, 2022

\begin{abstract}
Context: The resistance to pyrethroids in malaria vectors continues to grow in Africa and could therefore compromise or reduce substantially the effectiveness of LLINs in preventing malaria. It is therefore of paramount importance to evaluate the protective efficacy of LLINs in children sleeping in areas of vector resistance to insecticides in order to draw lessons for future interventions. This study assesses the effect of the use of LLINs on malaria morbidity in clusters of low and high resistance of vectors to pyrethroids. Methods: This is a cross-sectional case-control study with one control for one case that was conducted in the communes of Kétou, Ifangni, Kétou, and Pobè in the Plateau department of southern Benin. The use of LLINs and malaria morbidity was measured and compared in children from clusters of low and high vector resistance to insecticides. In each commune, 30 cases and 30 controls were recruited for a total of 240 children under 5 years of age from villages with low and high insecticide resistance. Results: According to the localities of origin of the children, of all parents of children surveyed, 169
\end{abstract}


Copyright (C) 2022 by author(s) and Scientific Research Publishing Inc. This work is licensed under the Creative Commons Attribution International License (CC BY 4.0).

http://creativecommons.org/licenses/by/4.0/
(70.4\%) asserted the children slept under an LLIN the day before they arrived at the health center. This rate represents $70.8 \%$ ( 85 children) among the cases and $70.0 \%$ (84 children) among the controls without significant difference $(\mathrm{p}=0.8)$. The use of LLINs the day before the survey, the frequency of their use during the two weeks preceding the day of the survey, their availability at the household level, the use of other tools for protection against mosquito bites are the same in the two groups of children (cases and controls) $(p>0.05)$ as well in low and high resistance villages. On the other hand, the parasite prevalence, the splenomegaly and the geometric means of the parasite densities, are significantly higher in the cases than in the controls $(p<0.05)$. Conclusion: The evaluation of epidemiological indicators in children under five years old at the level of health centers did not enable demonstrating the impact of resistance on the operational effectiveness of the LLINs. The information collected within the four health facilities only reflects the situation that should normally be seen in the population under the real conditions of use of LLINs in high and low resistance areas.

\section{Keywords}

Case-Controls, LLINs, Malaria Morbidity, Pyrethroids Resistance, Benin

\section{Background}

Malaria control is a priority for health authorities in endemic countries. As part of the prevention of this disease, vector control is a very important and closely monitored axis [1]. LLINs are the main tool of the fight and a lot of efforts are made to increase their accessibility to populations, in particular children under five and pregnant women. The Demographic Health Survey conducted in Benin in 2006 showed that only 33\% of children under five and 32\% of pregnant women slept under an LLIN [2]. These rates are far below the $80 \%$ coverage threshold recommended by the World Health Organization [3]. However, with the targeted campaign of October 2007 and the one aiming the universal access of populations in July 2011, the coverage and use of LLINs in Benin have been markedly improved [4] [5]. Thus, results from the EDS-V [6] showed a better possession and use of LLINs in children under five and pregnant women. Usage rates reached $79.7 \%$ and $87.4 \%$ among children under five and pregnant women respectively, with an average number of 2.3 LLINs per household.

The success of LLINs in preventing malaria stems from the fact that they provide both an effective individual protection for its users, as well as a community one if the coverage rate is high enough to decrease the ability of vectors in transmitting the parasite [3] [7]. Unfortunately, resistance to pyrethroids in malaria vectors continues to grow in Africa [8] and could therefore compromise or reduce substantially the effectiveness of LLINs in preventing malaria. It is therefore of paramount importance to evaluate the protective efficacy of LLINs in children sleeping in areas of vector resistance to insecticides in order to draw 
lessons for future interventions. The general objective of this study was to assess the effect of the use of LLINs on malaria morbidity in clusters of low and high resistance of vectors to pyrethroids.

Specifically, the present article aims to:

- determine malaria morbidity in children under 5 years old in two zones of different resistance level (low and high);

- determine the proportion of fever cases without $P$. falciparum in children under 5 years old;

- determine the asymptomatic carriage of $P$. falciparum in children under 5 years old;

- determine the factors influencing the presence of $P$. falciparum in the blood;

- evaluate the protective efficacy of LLINs in children under 5 years old in the different clusters.

\section{Materials and Methods}

\subsection{Study Area}

The study occurred in the districts of Ifangni, Sakété, Pobè and Kétou located in the Plateau region, Benin. The region has an area of $3264 \mathrm{~km}^{2}$, for a total population of 407,116 inhabitants [9]. It is characterized by two rainy seasons (March to July and, September to November) and two dry seasons (December to March and August to September). In this department, a massive distribution of LLINs conducted by the national authorities occurred in 2007 as part of the malaria control activities in Benin. The climate is Guinean-type. The main activities are trading and agriculture.

In the four districts mentioned above, clusters with low and high resistance of malaria vectors to pyrethroid insecticides, and where the LLIN coverage was greater than or equal to $80 \%$ were investigated. Depending on the level of resistance, we compared the data obtained in the two groups of children (cases and controls), and also assessed the influence of resistance in the $\mathrm{R}+$ (Low resistance) and $\mathrm{R}^{3+}$ (high resistance) zones defined by Sovi et al. [10]. This baseline report enabled detecting the resistance status of malaria vectors in the cluster of origin of the children included in the study.

\subsection{Study Method}

\subsubsection{Type of Study, Sampling and Study Population}

This is a cross-sectional case-control study with progress recruitment with one control for a case that started in November 2011 and ended in July 2012 in the above-mentioned districts.

The required sample size of cases $\left(n_{1}\right)$ and controls $\left(n_{0}\right)$, was estimated by Formula (1) (Hayes \& Bennett, 1999):

$$
n_{0}=n_{1}=\frac{\left(Z_{1-\frac{\alpha}{2}}+Z_{1-\beta}\right)^{2}\left[p_{0}\left(1-p_{0}\right)+p_{1}\left(1-p_{1}\right)\right]}{\left(p_{0}-p_{1}\right)^{2}}
$$


$p_{1}$ is the prevalence of cases, and given the unavailability of an area-level estimator, it was set at 0.5 .

$p_{0}$ is the expected prevalence in the control group, it was set at 0.25 (a reduction of $50 \%$ compared to the group of cases).

$Z_{1-\frac{\alpha}{2}}$ is the order quantile $1-\frac{\alpha}{2}$ of the normal distribution, with, $\alpha$ the threshold set to 0 and

$Z_{1-\beta}$ is the order quantile $\frac{\beta}{2}$ of the normal distribution, with $\beta$ the power set to 0.8 .

Based on (1), the sample size was estimated to be around 60 children per groups from each zone ( $\mathrm{R}+$ and $\mathrm{R}+++$ zone). Thus the overall size of the sample was estimated at 240 children under 5 years old in each commune.

The sample was made up of all children under five years old residing in the study villages for at least 6 months and, having been received in medical consultation or in vaccination services and, whose parents have given their informed consent. The first 120 children under 5 years old with fever and the first 120 children under 5 years old without fever who were recruited, received medical consultation. Four referral health facilities have been identified in the four districts to house the work. These are the Kétou and Ifangni Health Centers, then the Sakété and Pobè Zone Hospitals. Recruitment in each health facility concerned the first 30 children under 5 years old with fever and the first 30 children under 5 years old without fever.

\subsubsection{Conduct of the Study}

- Training of actors: In each health facility, two nurses and two laboratory technicians were trained on the conduct of the study.

- Recruitment of children: Children under five years old who came for a medical consultation were subjected to a full clinical examination by the nurse.

* The nurse has:

- administered the information notice to obtain informed consent from parents;

- taken the temperature;

- completed the questionnaire and assigned a code to each child;

- sent the child to the laboratory technician;

- retrieved the results from the technician and recorded them on the questionnaire;

- treated sick children.

* The technician has:

- carried out the thick blood smear and the blood smear from a capillary sample;

- made the Dried blood spots (DBS; on Whatman 3 MM filter paper, GE Healthcare, Buckinglomshire, United Kingdom) to search for anti-salivary antibodies; 
- recorded the results in the laboratory notebook and in the book prepared for this purpose.

\subsubsection{Supervision of Activities}

This supervision was carried out by the study management team every two weeks and consisted of validating the questionnaires before the training, the completed consent forms, as well as the laboratory activities (microscopy preparation of the slides and the confetti). The supervision team reviewed the practical organization of the activities in the field. The sheets of questionnaire were collected at each supervision round as part of the data management. Ten percent (10\%) of the microscopy prepared were subjected to quality control in the laboratory of the Hôpital de la Mère et de l'Enfant Lagune in Cotonou.

\subsubsection{Preparation, Coloration and Reading of the Thick Blood Smear (TBS)/Blood Smear (BS)}

Blood smears and thick Blood smears were carried out on labeled slides. These slides were stained with $10 \%$ Giemsa. They were dried and then read under a microscope with an $\times 100$ objective. The parasite density was determined and the species of plasmodium is indicated after reading.

$$
\text { Parasite Density }=\frac{\text { Number of counted parasites }}{\text { Number of counted blood cells }} \times 8000
$$

${ }^{\star} 1 \mu \mathrm{L}$ of blood contains an average of 8000 white blood cells.

\subsubsection{Numbering System of the Sample}

Once included, the patient case record sheet should be easily accessible at each visit. To do this, a unique identification number has been assigned to each patient. Similarly, filter papers and slides from each patient were identified with the same number from the start to the end of the study. If a number is incorrectly written or if the same number is assigned to two different patients, these records have not been used and were lost. The example below illustrates how to assign and record the ID number for a slide. It was repeated on the patient records and on subsequent filter papers and slides.

Example: If the patient comes from site $\mathrm{N}^{\circ} 01$ of BENIN (BJ), is the first one of the study, and recruited on 02/14/2005, his number is 01BJ001, and the slide will be labelled as follows (Figure 1):

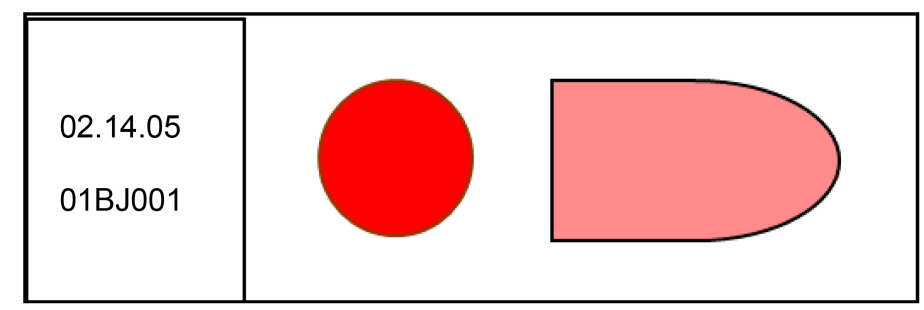

Figure 1. Identification system for a thick blood smear slide ready to be stained. 02.14.05 = Study date; $01=$ Site $\mathrm{N}^{\circ} 1$; $\mathrm{BJ}=\mathrm{BENIN} ; 001=$ Patient $\mathrm{N}^{\circ} 1$. 


\subsubsection{Case Management}

All malaria cases were managed by the study according to national policy. All other cases were transferred to the hospital for treatment through the normal circuit.

\subsubsection{Ethical Considerations}

The study was submitted to the National Ethics Committee for Health Research of Benin, which gave its agreement (Agreement $\mathrm{N}^{\circ} 007$ of May 25, 2010). The informed consent of the parents of children was obtained in written form. Data confidentiality and anonymity were respected. The support of checkups and treatment of simple malaria was free. An information leaflet stating the study objectives, advantages, risks and disadvantages was read to study participants.

\subsubsection{Data Management and Analysis}

A double entry of the data was performed using the Epi data software. Data analyzes were performed using SPSS 16.0 software on the one hand and, for the evaluation of the mean parasite densities. All differences were considered significant at $\mathrm{p}<0.05$.

- The parasitological indices were calculated in terms of the prevalence of Plasmodium falciparum and the parasite density of asexual forms of $P$. falciparum $/ \mu \mathrm{L}$ of blood. The mean parasite density was calculated in parasitologically positive individuals after logarithmic transformation.

- The association between prevalence, use of LLINs, splenomegaly, geometric means of parasite densities was tested by a logistic regression model, taking into account the clinical status (cases versus control), and also according to the status of clusters of origin. The fraction of fevers attributable to malaria is estimated from odds ratios associated with parasite densities estimated in the model [11].

- The preventive fractions of interventions against simple malaria attacks were calculated in cases and controls and in healthcare facilities from the odds ratios obtained in the case-control studies $(\mathrm{FP}=1-\mathrm{OR})$.

\section{Results}

From December 2011 to July 2012, 240 children were recruited from the 4 health facilities involved in the study. A total of 55 under five years old children were tested positive, with minimum and maximum levels of 64 and, 178,400 parasites per microliter of blood, respectively. Characteristics of Parasite Densities (PD) for the 120 cases were as follows: minimum 128; maximum 128,000; average 29,096 and median 6480. For the 120 controls, the PD displayed the following characteristics: minimum 64; maximum 178,400; Mean 34,352 and median 13,680 . The median age of the children was 21 months (minimum 1 and maximum 59 months). The sex ratio (M/F) was 1.01 . The 120 children called cases (i.e. those suffering from malaria and having an axillary temperature above $37.5^{\circ} \mathrm{C}$ ) and, the 120 control ones were randomly selected according to their ori- 
gin and their order of arrival in the health center. A questionnaire has been administered to their mothers or guardians.

\subsection{Evaluation of Variables in Cases and Controls}

According to the localities of origin of the children, of all parents of children surveyed, $169(70.4 \%)$ asserted the children slept under a LLIN the day before they arrived at the health center. This rate represents $70.8 \%$ ( 85 children) among the cases and $70.0 \%$ ( 84 children) among the controls without significant difference $(\mathrm{p}=0.8)$. When considering the status of the clusters, the rate of use of LLINs was $68.0 \%$ in the high resistance zone and $74.2 \%$ (69 children) in the low resistance zone without significant difference $(\mathrm{p}=0.3)$ (Table 1$)$. The use of LLINs the day before the survey, the frequency of their use during the two weeks preceding the day of the survey, their availability at the household level, the use of other tools for protection against mosquito bites are the same in the two

Table 1. Evaluation of epidemiological variables in cases and controls as a function of areas of high and low resistance of vectors.

\begin{tabular}{|c|c|c|c|c|c|c|c|c|c|c|}
\hline \multirow{3}{*}{ Variables } & \multicolumn{5}{|c|}{ Low resistance area $(\mathrm{R}+)$} & \multicolumn{5}{|c|}{ High resistance area $(\mathrm{R}+++)$} \\
\hline & \multicolumn{2}{|c|}{ Case } & \multicolumn{2}{|c|}{ Control } & \multirow{2}{*}{$\mathrm{P}$-value } & \multicolumn{2}{|c|}{ Case } & \multicolumn{2}{|c|}{ Control } & \multirow{2}{*}{ P-value } \\
\hline & $\mathrm{N}$ & $\%$ & $\mathrm{~N}$ & $\%$ & & $\mathrm{~N}$ & $\%$ & $\mathrm{~N}$ & $\%$ & \\
\hline \multicolumn{11}{|l|}{ LLINs usage } \\
\hline Yes & 11 & 24.4 & 13 & 27.1 & \multirow{2}{*}{0.771} & 24 & 32.0 & 23 & 31.9 & \multirow{2}{*}{0.994} \\
\hline No & 34 & 75.6 & 35 & 72.9 & & 51 & 68.0 & 49 & 68.1 & \\
\hline \multicolumn{11}{|l|}{ Age group } \\
\hline $9-23$ mois & 18 & 40.0 & 43 & 89.6 & \multirow{2}{*}{0.000} & 3 & 4.0 & 12 & 16.7 & \multirow{2}{*}{0.011} \\
\hline $24-59$ mois & 27 & 60.0 & 05 & 10.4 & & 72 & 96.0 & 60 & 83.3 & \\
\hline \multicolumn{11}{|l|}{ LLIN Availability } \\
\hline Yes & 42 & 93.3 & 44 & 91.7 & \multirow{2}{*}{0.617} & 66 & 88.0 & 66 & 91.7 & \multirow{2}{*}{0.463} \\
\hline No & 03 & 6.7 & 4 & 8.3 & & 9 & 12.0 & 6 & 8.3 & \\
\hline \multirow{2}{*}{\multicolumn{11}{|c|}{$\begin{array}{l}\text { Use of other means of } \\
\text { Vector Control }\end{array}$}} \\
\hline & & & & & & & & & & \\
\hline Yes & 8 & 17.8 & 13 & 27.1 & \multirow{2}{*}{0.293} & 17 & 22.7 & 9 & 12.5 & \multirow{2}{*}{0.106} \\
\hline No & 37 & 82.2 & 35 & 72.9 & & 58 & 77.3 & 63 & 87.5 & \\
\hline \multicolumn{11}{|c|}{ Frequency of LLINs usage } \\
\hline Always & 23 & 51.1 & 23 & 47.9 & \multirow{4}{*}{0.757} & 34 & 45.3 & 37 & 51.4 & \multirow{4}{*}{0.321} \\
\hline Often & 8 & 17.8 & 10 & 20.9 & & 17 & 22.5 & 8 & 11.1 & \\
\hline Rarely & 4 & 8.9 & 2 & 4.2 & & 5 & 6.7 & 6 & 8.3 & \\
\hline Never & 10 & 22.2 & 13 & 27.1 & & 19 & 25.3 & 21 & 29.2 & \\
\hline Parasite prevalence & 18 & 19.4 & 6 & 6.5 & 0.002 & 21 & 14.3 & 10 & 6.8 & 0.036 \\
\hline Splenomegaly & 13 & 14.0 & 4 & 4.3 & 0.010 & 15 & 10.2 & 3 & 4.1 & 0.03 \\
\hline $\begin{array}{l}\text { Geometric mean of } \\
\text { parasite densities }\end{array}$ & 103.4 & & 2.641 & & 0.0014 & 6.405 & & 3.907 & & 0.325 \\
\hline
\end{tabular}


groups of children (cases and controls) ( $\mathrm{p}>0.05)$ as well in low and high resistance villages. On the other hand, the parasite prevalence, the splenomegaly and the geometric means of the parasite densities, are significantly higher in the cases than in the controls $(\mathrm{p}<0.05)$.

The number of children having their thick blood smear (TBS) positive among the cases was 39 equating to $32.5 \%$, against 16 equating to $13.3 \%$ among the controls. Thus, approximately 1 out of 3 children showed a positive parasitaemia in those who had fever.

Since all fevers are not due to malaria, we defined fevers attributable to malaria as the presence of hyperthermia (axillary temperature $=37.5^{\circ} \mathrm{C}$ ) associated with the presence of $P$. falciparum. The overall prevalence of malaria was $32.5 \%$ when considering all cases and controls in all areas. When considering the origins of children, in high resistance clusters, the parasite prevalence was higher in cases than in controls $(p=0.036)$ and this difference is similar in areas of low resistance $(\mathrm{p}=0.002)$.

It is also observed that the splenic index, which in addition to being higher among cases than controls $(\mathrm{p}=0.000)$, which is normal, is also higher among cases in high resistance localities $(\mathrm{p}=0.010)$ and similar in low resistance areas $(p=0.03)$. The geometric mean of parasite densities is higher in cases than in controls in low resistance areas $(p=0.001)$ and higher in high vector resistance areas without significant differences $(\mathrm{p}=0.325)$. Thus, we note that the geometric means of Parasite Densities (PD) are higher in high resistance areas compared to low resistance areas. This difference in results could be explained by the fact that there were more positive children (21 positive children in the cases) in the high resistance zones $(\mathrm{R}+++)$ compared to 18 positive children in the cases in low resistance zones $(\mathrm{R}+)$.

In low and high resistance areas, the geometric mean of parasite densities was about ten times $(\mathrm{p}=0.001)$ and nearly four times $(\mathrm{p}=0.325)$ higher in the cases than in the controls, respectively. Similarly the splenic index, which in addition to being higher in the cases than in the controls $(\mathrm{p}=0.000)$ was also higher in high resistance villages compared to low resistance ones. The geometric means of the parasite densities were higher in areas of high resistance.

\subsection{Factors Associated with the Presence of Plasmodium falciparum in the Blood of All Children}

The results of the multivariate analyzes performed on all variables assumed to influence the presence of the parasite in children in the different localities reveal that, the age of the children, the splenomegaly, the use of other means of prevention, the parasite prevalence, the age of LLINs use are linked to the occurrence of malaria and (Table 2).

\subsection{Protective Efficacy of LLINs Used by Children}

For all the children, the negative controls slept under a LLIN the day before the survey in the same way as the children suffering from malaria $(69.23 \%$ versus 
Table 2. Factors associated with the presence of Plasmodium falciparum in the blood of children of the study.

\begin{tabular}{cccccc}
\hline Associated Factors & $\begin{array}{c}\text { Odds Ratio } \\
(95 \% \text { C.I. })\end{array}$ & $\begin{array}{c}\text { Coefficient } \\
\text { Bêta }\end{array}$ & S.D. & $\begin{array}{c}\text { Test } \\
\text { Wald }\end{array}$ & p-value \\
\hline 0 à 23 months & - & - & - & - & - \\
\hline 24 à 59 month $(\mathbf{s})$ & $2.945(1.452 ; 5.973)$ & 1.08 & 0.361 & 8.962 & 0.003 \\
$\quad$ Splenomegaly & $0.102(0.044 ; 0.237)$ & -2.284 & 0.432 & 27.967 & 0.000 \\
$\begin{array}{c}\text { Age of LLINs } \\
\text { Use of other means } \\
\text { of protection }\end{array}$ & $0.936(0.885 ; 0.989)$ & -0.067 & 0.028 & 5.622 & 0.018 \\
\begin{tabular}{c} 
Infestation (TBS) \\
\hline
\end{tabular} & 3.47 & -0.874 & 0.37 & 5.576 & 0.018 \\
\hline
\end{tabular}

C.I.: Confidence Interval, S.D.: Standard of Deviation.

69.23\%, OR $=1$; and 95\% CI [0.45 - 2.22]. In both low and high resistance areas, the protective fraction $(\mathrm{PE}=1-\mathrm{OR})$ was similar (Table 3$)$. An effect of the universal coverage of LLINs occurred, which was not the case of the level of vector resistance to insecticides.

\subsection{Influence of Resistance on the Epidemiological Parameters of Children in the Study}

Data analysis performed with the following variables: "use of LLINs, splenomegaly, parasite prevalence, with the variable, low or high resistance level of vectors to insecticides" is presented in Table 4 .

The logistic regression model used, showed that the use of an LLIN the day before the survey was constant in the low resistance area than in the high resistance one. Splenomegaly and parasite prevalence do not better explain the effect of vector resistance on malaria from which children under 5 years suffer and that was assessed at the health center at the case and control level.

\section{Discussion}

Epidemiological indicators assessed in children under five years old have failed to demonstrate the impact of vector resistance on the efficacy of LLINs. The information collected within the four health facilities only reflects the situation that should normally be seen in the population under the real conditions of use of LLINs in high and low resistance areas. The expected protective efficacy of the use of LLINs against malaria morbidity in children under 5 years old was assessed on the basis of information received from mothers or caregivers who came to health care facilities to request for the services of health workers.

This study is consistent with other results on insecticide impact that have reported lack of evidence on the implications of vector resistance to malaria control interventions [12] [13] [14] [15]. Other work [16] [17] indicated that LLINs continue to protect users and that no association was found between insecticide 
Table 3. Analysis of the efficacy conferred by LLINs in negative controls and children with malaria.

\begin{tabular}{|c|c|c|c|c|c|c|c|c|c|}
\hline \multirow{2}{*}{ Variables } & \multicolumn{2}{|c|}{ Cases+ } & \multicolumn{2}{|c|}{ Control- } & \multirow{2}{*}{\multicolumn{2}{|c|}{ OR }} & \multirow{2}{*}{ IC95\% } & \multirow{2}{*}{ EP } & \multirow{2}{*}{$\mathrm{p}$} \\
\hline & $\mathbf{n}$ & $\%$ & $\mathrm{n}$ & $\%$ & & & & & \\
\hline \multicolumn{10}{|c|}{ Use of LLINs in the study area } \\
\hline Yes & 27 & 69.23 & 72 & 69.23 & 1 & & & & \\
\hline No & 12 & 30.77 & 32 & 30.77 & 1 & 0.45 & 2.22 & 0.0 & 1.00 \\
\hline \multicolumn{10}{|c|}{$\begin{array}{l}\text { Use of LLINs in the low resistance } \\
\text { area }\end{array}$} \\
\hline Yes & 14 & 74.07 & 32 & 75.56 & 1 & & & & \\
\hline No & 04 & 25.93 & 10 & 24.44 & 1.09 & 0.29 & 4.09 & -0.09 & 0.0 .89 \\
\hline \multicolumn{10}{|c|}{$\begin{array}{l}\text { Use of LLINs in the high resistance } \\
\text { area }\end{array}$} \\
\hline Yes & 13 & 70.37 & 40 & 68.0 & 1 & & & & \\
\hline No & 08 & 29.63 & 22 & 32.0 & 0.89 & 0.32 & 2.49 & 0.11 & 0.83 \\
\hline
\end{tabular}

Protective Efficacy $(\mathrm{PE}=1-\mathrm{OR})$.

Table 4. Analysis of the parameters associated with the resistance status of the villages of origin of the children.

\begin{tabular}{|c|c|c|c|c|c|c|}
\hline Source of variables & Parameters & Modality & Coefficient & Odds Ratio & C.I. $95 \%$ & P-Value \\
\hline \multirow{6}{*}{ Case } & \multirow{2}{*}{ Use of LLINs } & $\mathrm{R}+$ & 0.000 & 1.00 & - & - \\
\hline & & R3+ & -0.3747 & 0.6875 & {$[0.2982 ; 1.5849]$} & 0.3792 \\
\hline & \multirow{2}{*}{ Splenomegaly } & $\mathrm{R}+$ & 0.000 & 1.00 & - & - \\
\hline & & $\mathrm{R}+++$ & -0.4855 & 0.6154 & {$[0.261 ; 1.4509]$} & 0.2672 \\
\hline & \multirow{2}{*}{ Parasite Prevalence } & $\mathrm{R}+$ & 0.000 & 1.00 & - & - \\
\hline & & $\mathrm{R}+++$ & -0.539 & 0.5833 & {$[0.2672 ; 1.2736]$} & 0.1761 \\
\hline \multirow{6}{*}{ Control } & \multirow{2}{*}{ Use of LLINs } & $\mathrm{R}+$ & 0.000 & 1.00 & - & - \\
\hline & & $\mathrm{R}+++$ & -0.2341 & 0.7913 & {$[0.3532 ; 1.7728]$} & 0.5695 \\
\hline & \multirow{2}{*}{ Splenomegaly } & $\mathrm{R}+$ & 0.000 & 1.00 & - & - \\
\hline & & $\mathrm{R}+++$ & -0.7376 & 0.4783 & {$[0.1022 ; 2.2374]$} & 0.3488 \\
\hline & \multirow{2}{*}{ Parasite Prevalence } & $\mathrm{R}+$ & 0.000 & 1.00 & - & - \\
\hline & & $\mathrm{R}+++$ & 0.1214 & 1.129 & {$[0.3814 ; 3.3422]$} & 0.8265 \\
\hline \multirow{6}{*}{ Total (Case + Control) } & \multirow{2}{*}{ Use of LLINs } & $\mathrm{R}+$ & 0.000 & 1.00 & - & - \\
\hline & & $\mathrm{R}+++$ & -0.301 & 0.7401 & {$[0.4145 ; 1.3212]$} & 0.3087 \\
\hline & \multirow{2}{*}{ Splenomegaly } & $\mathrm{R}+$ & 0.000 & 1.00 & - & - \\
\hline & & $\mathrm{R}+++$ & -0.4719 & 0.6238 & {$[0.3034 ; 1.2827]$} & 0.1995 \\
\hline & \multirow{2}{*}{ Parasite Prevalence } & $\mathrm{R}+$ & 0.000 & 1.00 & - & - \\
\hline & & $\mathrm{R}+++$ & -0.2636 & 0.7683 & {$[0.4172 ; 1.4148]$} & 0.3975 \\
\hline
\end{tabular}

( $\mathrm{R}+$ : Low resistance area, $\mathrm{R}+++$ : High resistance area). 
resistance in vectors and malaria case outcomes including malaria prevalence data, incidence of infection and incidence of clinical malaria actively detected through a cohort. Therefore, this study is consistent with previous findings addressing questions of the impact of vector resistance on vector control.

But what could explain the lack of association between vector resistance and malaria prevalence in locations where LLINs are the primary method of vector control? Recent work has attempted to explain this by several reasons. First, even without insecticide, nets provide a physical barrier between the sleeper and the mosquito. Second, resistance is not an all-or-nothing phenomenon. The proportion of mosquitoes killed within 24 hours of exposure is reduced. The insecticide may still have an impact later. For example, a meta-analysis found that LLINs provided better protection than untreated nets [18], even in areas where mosquitoes were resistant to pyrethroids. There may also be more subtle effects at play; for example, oocyst development may be slower in resistant mosquitoes exposed to pyrethroids than in non-resistant mosquitoes [19].

Previous work has shown that routine clinical malaria case data collected at different health centers failed to show the contribution of vector resistance to malaria case progression [20]. Our study used a case-control methodology different from three other methodologies already used, namely cross-sectional surveys, routine health center data monitoring, and active cohort monitoring of children under five years of age, all of which led to the same results in estimating the impact of resistance on malaria cases or even prevalence. This removes any doubt about the validity of the results obtained in our study.

The present study enabled to confirm once again the better understanding of malaria that the actors involved in the case management should have. If by continuing to see the interventions as they are, without taking into account the environmental requirements of the vectors which change their behavior, the development of resistance by the vectors for example, we are in a straight line to have the expected results. Several trials carried out after distribution of LLINs to the populations have focused on their acceptability, their use [21] [22], their protective efficacy [23] [24] [25] [26] [27], their physical integrity, the bioavailability of the insecticide on them [28] [29] and their loss or increase in effectiveness under controlled conditions [30] [31] [32].

To our knowledge, this work is one of the first to make the link between the impact of vector resistance on cases received at health facilities and the existence of resistant vectors at the level of clusters of origin of patient in a case-control approach.

It allowed understanding that one out of three cases of fever observed in health facilities is malaria. This information is crucial for malaria control programs and input managers who will need to work to enforce malaria control guidelines and policies that recommend systematic confirmation of cases prior to treatment [1] [3] [33].

In the field of vector control, Rogier et al. [25] developed a model for evaluat- 
ing the use of LLINs in a non-paired case-control study at the community level in order to demonstrate a decrease in malaria attacks among users of LLINs. In this case and depending on the period, the level of LLIN coverage and the endemicity of malaria, the possibility of finding non-febrile children is high to constitute the control arm as recommended by the WHO (WHO, 2020) [1].

To reduce bias, each health facility recruited cases and controls at the same time. The possibility of finding children without fever to constitute the control population was low due to the low use of health services by children apparently healthy. Since fever is the primary reason for consultation in health facilities, the definition of cases and control was not very specific in our study. Indeed, it is well known that the symptomatology of uncomplicated malaria is not very specific. Also its best definition is based on the presence of symptoms evoking malaria associated with a parasite density greater than the pyrogenic threshold of parasitaemia [34]. All health facilities identified to house the work have a laboratory and a permanent team capable of confirming through the TBS, and recruiting cases in both night and day. The work lasted more than eight months for each team to be able to identify 30 cases and 30 controls. We had to move the teams to carry out days of duty in the district health centers closer to the study villages and which are in the same health area of the study village.

The questionnaires were administered by trained nurses so as, not to suggest the answer to the mother or caregiver. The question of LLIN use the day before the survey is the one used by the WHO in all of its surveys. Laboratory technicians sampled the TBS and confetti as soon as the control was identified.

In this study, the use of LLINs by children under five attending health facilities is high, around $70 \%$. This might be due to the fact that the survey took place immediately after the nationwide campaign for universal distribution of LLINs. The same observation was made by Ossè et al. [35] who obtained $80 \%$ usage rate in the same area. It would also be interesting to note that young age (less than 2 years) and the use of other tools for prevention against malaria vectors are determining factors in the occurrence of malaria. It is clear from these facts that it is necessary to increase the awareness of populations on the use of LLINs. This will help maintaining the gains in terms of malaria protection which was obtained through the level of use of LLINs by children, especially in the dry season.

The present trial shows that the use of LLINs received in health facilities by children ( $<5$ years old) was similar in areas of high or low resistance of vectors to insecticides, five to ten months after the July 2011 campaign.

To assess the protective efficacy of LLINs, the definitions of cases and controls had to be improved. Thus, the definition of cases based on the presence of symptoms evoking malaria (established fever) was supplemented by positive TBS, in accordance with the WHO recommendations [1] to treat simple malaria attacks with artemisinin-based combination therapies. The control was defined by the absence of fever and a negative TBS.

In the present trial, the protective efficacy of LLINs was similar in the two 
surveyed areas [20] in both cases and controls. The estimates of the efficacy of the LLINs, which were of about $50 \%$ in endemic areas where Anopheles are susceptible to insecticides [14] were not observed in our study. It should be noted that in the Lengeler's study, these measurements were carried out during phase III trials (WHOPES) where, by definition, the conditions for intervention and evaluation were optimal (almost all the children sleep everyday under LLINs which are in perfect condition). The usage rates of LLINs obtained in this study are close to those obtained during the evaluation of the national campaign, which in fact constitutes the most accurate information obtained within households [36]. Our assessment method was unable to establish a link between the use of LLINs and the level of vector resistance to insecticides. Furthermore, resistance of An. gambiae s.l. to pyrethroid insecticides in the area should not be overlooked. Ideally, it would have been interesting to have a resistant versus a fully susceptible area to demonstrate the impact of resistance on the operational effectiveness of vector control interventions.

The results of the work evaluating malaria transmission conducted in the study area over the same period did not note any difference between the low and high resistance areas [37].

This study has limitations. Firstly, there was no direct observation of the protection offered by LLINs in children and the information collected is declarative from parents and caregivers of children at the health center. Instead, it must be inferred at the ecological level from the fact that, although LLINs are the main form of malaria control in the study area, malaria prevalence was not higher in villages where resistance was higher. Secondly, many interesting aspects are present in this study. Cases and controls were identified in the community, simultaneously from the same at-risk population, however, recruitment from health centers may be a source of information bias, especially with respect to exposure variables. Because LLINs were distributed free of charge, mothers may lie (prevarication bias) about their child's exposure, especially in the health center area when children were sick to receive care. Thirdly, in addition to personal protection, LLINs can also provide protection through mass effect, killing mosquitoes, which reduces the longevity and density of local mosquitoes and provides protection to all community members, including those who do not use LLINs. The study was unable to differentiate between these two types of protection. Fourthly, the measure of insecticide resistance was based on the WHO insecticide susceptibility test, simply measuring the frequency of resistant vectors. Measures of resistance intensity based on a dose-response relationship that captures resistance intensity may be more informative, but were not practical at the scale of this study [38].

\section{Conclusion}

The evaluation of epidemiological indicators in children under five years old at the level of health centers did not enable to demonstrate the impact of resistance 
on the operational effectiveness of the LLINs. This is due to how the $\mathrm{R}+$ and $\mathrm{R}+++$ zones were selected. Indeed there is a very thin between the $\mathrm{R}+$ and $\mathrm{R}+++$ areas. There is a resistance threshold which has already been reached in both areas. We need a fully susceptible area and a resistant area.

\section{Conflicts of Interest}

The authors declare no conflicts of interest regarding the publication of this paper.

\section{References}

[1] WHO (2020) World Malaria Report 2020. World health Organization, Geneva.

[2] Institut National de la Statistique et de l'Analyse Économique (INSAE) (2006) Enquête démographique et de santé et à indicateurs multiples du Bénin eds-mics-iii 2006. Cotonou.

[3] WHO (2019) World Malaria Report 2019. World Health Organization, Geneva.

[4] Institut National de la Statistique et de l'Analyse Économique (INSAE) (2012) Enquête démographique et de santé et à indicateurs multiples du Bénin EDS-IV 2011-2012. Cotonou.

[5] Tokponnon, F.T, Aholoukpe, B., Denon, E.Y., Gnanguenon, V., Bokossa, A., N'guessan, R., Oke, M., Gazard, D.K. and Akogbeto, M.C. (2013) Evaluation of the Coverage and Effective Use Rate of Long-Lasting Insecticidal Nets after Nation-Wide Scale Up of Their Distribution in Benin. Parasites \& Vectors, 6, Article No. 265. https://doi.org/10.1186/1756-3305-6-265

[6] Institut National de la Statistique et de l'Analyse Économique (INSAE) (2018) Enquête démographique et de santé et à indicateurs multiples du Bénin EDS-V 2017-2018. Cotonou.

[7] WHO (2021) World Malaria Report 2021. World Health Organization, Geneva.

[8] Ranson, H. and Lissenden, N. (2016) Insecticide Resistance in African Anopheles Mosquitoes: A Worsening Situation That Needs Urgent Action to Maintain Malaria Control. Trends Parasitology, 32,187-196. https://doi.org/10.1016/j.pt.2015.11.010

[9] RGPH (2002) Deuxième recensement général de la population au Bénin.

[10] Sovi, A., Djègbè, I., Soumanou, L., Tokponnon, F., Gnanguenon, V., Azondékon, R., Oké-Agbo, F., Okè, M., Adéchoubou, A., Massougbodji, A., Corbel, V. and Akogbéto, M. (2014) Microdistribution of the Resistance of Malaria Vectors to Deltamethrin in the Region of Plateau (Southeastern Benin) in Preparation for an Assessment of the Impact of Resistance on the Effectiveness of Long Lasting Insecticidal Nets (LLINs). BMC Infectious Disease, 14, Article No. 103. https://doi.org/10.1186/1471-2334-14-103

[11] Schellenberg, M.P., Waddington, J. and King, J.R. (1994). Sod-Seeding Alfalfa in Spring into Established Crested Wheatgrass in Southwest Saskatchewan. Canadian Journal of Plant Science, 74, 293-301. https://doi.org/10.4141/cjps94-057

[12] Kafy, H.T., Ismail, B.A., Mnzava, A.P., Lines, J., Abdin, M.S.E., Eltaher, J.S., Banaga, A.B., West, P., Bradley, J., Cook, J., Thomas, B., Subramaniam, K., Hemingway, J., Knox, T.B., Malik, E.M., Yukich, J.O., Donnelly, M.J. and Kleinschmidt, I. (2017) Impact of Insecticide Resistance in Anopheles arabiensis on Malaria Incidence and Prevalence in Sudan and the Costs of Mitigation. Proceedings of the National Academy of Sciences of the United States of America, 114, E11267-E11275. 
https://doi.org/10.1073/pnas.1713814114

[13] Bradley, J., Ogouyemi-Hounto, A., Cornelie, S., Fassinou, J., de Tove, Y.S.S., Adeothy, A.A., Tokponnon, F.T., Makoutode, P., Adechoubou, A., Legba, T., Houansou, T., Kinde-Gazard, D., Akogbeto, M.C., Massougbodji, A., Knox, T.B., Donnelly, M. and Kleinschmidt, I. (2017) Insecticide-Treated Nets Provide Protection against Malaria to Children in an Area of Insecticide Resistance in Southern Benin. Malaria Journal, 16, Article No. 225. https://doi.org/10.1186/s12936-017-1873-1

[14] Kleinschmidt, I., Bradley, J., Knox, T.B., Mnzava, A.P., Kafy, H.T., Mbogo, C., Ismail, B.A., Bigoga, J.D., Alioun Adechoubou, A., Raghavendra, K., Cook, J., Malik, E.M., Nkuni, Z.J., Macdonald, M., Bayoh, N., Ochomo, E., Fondjo, E., Awono-Ambene, H.P., Etang, J., Akogbeto, M., Bhatt, R.M., Chourasia, M.K., Swain, D.K., Kinyari, T., Subramaniam, K., Massougbodji, A., Okê-Sopoh, M., Ogouyemi-Hounto, A., Kouambeng, C., Abdin, M.S., West, P., Elmardi, K., Cornelie, S., Corbel, V., Valecha, N., Mathenge, E., Kamau, L., Lines, J. and Donnelly, M.J. (2018) Implications of Insecticide Resistance for Malaria Vector Control with Long-Lasting Insecticidal Nets: A WHO-Coordinated, Prospective, International, Observational Cohort Study. The Lancet Infectious Disease, 18, 640-649.

https://doi.org/10.1016/S1473-3099(18)30172-5

[15] Ochomo, E., Chahilu, M., Cook, J., Kinyari, T., Bayoh, N.M., West, P., Kamau, L., Osangale, A., Ombok, M., Njagi, K., Mathenge, E., Muthami, L., Subramaniam, K., Knox, T., Mnavaza, A., Donnelly, M.J., Kleinschmidt, I. and Mbogo, C. (2017) Insecticide-Treated Nets and Protection against Insecticide-Resistant Malaria Vectors in Western Kenya. Emerging Infectious Disease, 23, 758-764.

https://doi.org/10.3201/eid2305.161315

[16] Lindblade, K.A., Mwandama, D., Mzilahowa, T., Steinhardt, L., Gimnig, J., Shah, M., Bauleni, A., Wong, J., Wiegand, R., Howell, P., Zoya, J., Chiphwanya, J. and Mathanga, D.P. (2015) A Cohort Study of the Efectiveness of Insecticide-Treated Bed Nets to Prevent Malaria in an Area of Moderate Pyrethroid Resistance, Malawi. Malaria Journal, 14, Article No. 31. https://doi.org/10.1186/s12936-015-0554-1

[17] Tokponnon, F., Ogouyémi, A., Sissinto, Y., Sovi, A., Gnanguenon, V., Cornélie, S., Adéothy, A., Ossè, R., Wakpo, A., Gbénou, D., Oke, M., Kinde-Gazard, D., Kleinschmidt, I., Akogbeto, M. and Massougbodji, A. (2014) Impact of Long-Lasting, Insecticidal Nets on Anaemia and Prevalence of Plasmodium falciparum among Children under Five Years in Areas with Highly Resistant Malaria Vectors. Malaria Journal, 13, Article No. 76. https://doi.org/10.1186/1475-2875-13-76

[18] Strode, C., Donegan, S., Garner, P., Enayati, A.A. and Hemingway, J. (2014) The Impact of Pyrethroid Resistance on the Efficacy of Insecticide-Treated Bed Nets against African Anopheline Mosquitoes: Systematic Review and Metaanalysis. PLoS Medicine, 11, e1001619. https://doi.org/10.1371/journal.pmed.1001619

[19] Kristan, M., Lines, J., Nuwa, A., Ntege, C., Meek, S.R. and Abeku, T.A. (2016) Exposure to Deltamethrin Affects Development of Plasmodium falciparum inside Wild Pyrethroid Resistant Anopheles gambiae s.s. Mosquitoes in Uganda. Parasites \& Vectors, 9, 100. https://doi.org/10.1186/s13071-016-1384-x

[20] Tokponnon, T.F., Sissinto,Y., Hounto Ogouyémi, A., Adéothy, A.A., Adechoubou, A., Houansou, T., Oke, M., Kinde-Gazard, D., Massougbodji, A., Akogbeto, M., Cornelie, S., Corbel, V., Knox, T.B., Mnzava, A.P., Donnelly, M.J., Kleinschmidt, I. and Bradley, J. (2019) Implications of Insecticide Resistance for Malaria Vector Control with long-Lasting Insecticidal Nets: Evidence from Health Facility Data from Benin. Malaria Journal, 18, Article No. 37.

https://doi.org/10.1186/s12936-019-2656-7 
[21] Ntuku, H.M., Ruckstuh, L., Emmanuel, J., Réminiac, J., Umesumbu, S.E., Bokota, A., Kitoto Tshefu, A. and Lengeler, C. (2017) Long-Lasting Insecticidal Net (LLIN) Ownership, Use and Cost of Implementation after a Mass Distribution Campaign in Kasaï Occidental Province, Democratic Republic of Congo. Malaria Journal, 16, Article No. 22. https://doi.org/10.1186/s12936-016-1671-1

[22] Harrison Arroz, J.A., Chirrute, F., Mendis, C., Chande, M.H. and Kollhoff, V. (2016) Assessment on the Ownership and Use of Mosquito Nets in Mozambique. Revue Saúde Pública, 50, 67. https://doi.org/10.1590/s1518-8787.2016050006335

[23] Lengeler, C. (2004) Insecticide-Treated Bed Nets and Curtains for Preventing Malaria. Cochrane Database Systematic Revue, No. 2, CD000363. https://doi.org/10.1002/14651858.CD000363.pub2

[24] Henry, M.C., Assi, S.B., Rogier, C., Yovo, D.J., Chandre, F., Guillet, P. and Carnevale, P. (2005) Protective Efficacy of Lambda-Cyhalothrin Treated Nets in Anopheles gambiae Pyrethroid Resistance Areas of Côte d'Ivoire. American Journal of Tropical Medicine and Hygiene, 73, 859-864. https://doi.org/10.4269/ajtmh.2005.73.859

[25] Rogier, C., Henry, M.C., Rowland, M., Carnevale, P., Chandre, F., Corbel, V., Curtis, C. and Hougard, J.M. (2009) Guidelines for Phase III Evaluation of Vector Control Methods against Malaria. Médecine Tropicale, 69, 173-184.

[26] Damien, G.B., Djènontin, A., Rogier, C., Corbel, V., Bangana, S.B., Chandre, F., Akogbeto, M., Kinde-Gazard, D., Massougbodji, A. and Henry, M.C. (2010) Malaria Infection and Disease in an Area with Pyrethroid-Resistant Vectors in Southern Benin. Malaria Journal, 9, Article No. 380. https://doi.org/10.1186/1475-2875-9-380

[27] Kouadio, I.K., Aljunid, S., Kamigaki, T., Hammad, K. and Oshitani, H. (2012) Infectious Diseases Following Natural Disasters: Prevention and Control Measures. Expert Review of Anti-Infective Therapy, 10, 95-104. https://doi.org/10.1586/eri.11.155

[28] Kilian, A., Hannah, K., Ebenezer, B., Emmanuel, O.O., Richmond, A.S., Lokko, K. and Lynch, M. (2013) Universal Coverage with Insecticide-Treated Nets-Applying the Revised Indicators for Ownership and Use to the Nigeria 2010 Malaria Indicator Survey Data. Malaria Journal, 12, Article No. 314. https://doi.org/10.1186/1475-2875-12-314

[29] Ahogni, I.B., Aïkpon, R.Y., Ossè, R.A., Dagnon, J.F., Govoetchan, R., Attolou, R.H., Agbevo, A., Azondekon, R., Koukpo, C.Z., Gnanguenon, V., Sagbohan, H., Kpanou, C., Tokponon, F., Akinro, B., Padonou, G.G. and Akogbeto, M.C. (2020) Field Durability of Yorkool ${ }^{\circledR}$ LN Nets in the Benin Republic. Advances in Entomology, 8, 72-92. https://doi.org/10.4236/ae.2020.81006

[30] N'Guessan, R., Corbel, V., Bonnet, J., Yates, A., Asidi, A., Boko, P., Odjo, A., Akogbéto, M. and Rowland, M. (2007) Evaluation of Indoxacarb, an Oxadiazine Insecticide for the Control of Pyrethroid-Resistant Anopheles gambiae (Diptera: Culicidae). Journal of Medical Entomology, 44, 270-276. https://doi.org/10.1093/jmedent/44.2.270

[31] Asidi, A., N'Guessan, R., Akogbeto, M., Curtis, C. and Rowland, M. (2012) Loss of Household Protection from Use of Insecticide-Treated Nets against Pyrethroid-Resistant Mosquitoes, Benin. Emerging Infectious Disease, 18, 1101-1106. https://doi.org/10.3201/eid1807.120218

[32] Briët, O.J., Amerasinghe, P.H. and Vounatsou, P. (2013) Generalized Seasonal Autoregressive Integrated Moving Average Models for Count Data with Application to Malaria Time Series with Low Case Numbers. PLoS ONE, 8, e65761. 
https://doi.org/10.1371/journal.pone.0065761

[33] PNLP (2011) Plan Stratégie National de Lutte contre le Paludisme en 2011 au Bénin. Cotonou, $70 \mathrm{p}$.

[34] Alonso, P.L., Smith, T., Armstrong Schellenberg, J.R.M., Masanja, H., Mwankusye, S., et al. (1994) Randomised Trial of Efficacy of SPf66 Vaccine against Plasmodium falciparum Malaria in Children in Southern Tanzania. The Lancet, 344, 1175-1181. https://doi.org/10.1016/S0140-6736(94)90505-3

[35] Ossè, R., Aikpon, R., Padonou, G.G., Oussou, O., Yadouléton, A. and Akogbéto, M. (2012) Evaluation of the Efficacy of Bendiocarb in Indoor Residual Spraying against Pyrethroid Resistant Malaria Vectors in Benin: Results of the Third Campaign. Parasites \& Vectors, 5, Article No. 163. https://doi.org/10.1186/1756-3305-5-163

[36] PNLP (2020) Campagne Nationale de Distribution Gratuite de Moustiquaires Imprégnées d'Insecticide à Longue Durée d'action aux Ménages. Rapport général de fin de la campagne, Bénin, $68 \mathrm{p}$.

[37] Sovi, A., Azondékon, R., Aikpon, R.Y., Govoétchan, R., Tokponnon, F., Agossa, F., Salako, A.S., Oké-Agbo, F., Aholoukpè, B., Okè, M., Gbénou, D., Massougbodji, A. and Akogbéto, M. (2013) Impact of Operational Effectiveness of Long-Lasting Insecticidal Nets (LLINs) on Malaria Transmission in Pyrethroid-Resistant Areas. Parasites \& Vectors, 6, Article No. 319. https://doi.org/10.1186/1756-3305-6-319

[38] Donnelly, M.J., Isaacs, A.T. and Weetman, D. (2016) Identification, Validation, and Application of Molecular Diagnostics for Insecticide Resistance in Malaria Vectors. Trends in Parasitology, 32, 197-206. https://doi.org/10.1016/j.pt.2015.12.001 